\title{
Bridging the Intention-Behavior Gap: Effect of Altruistic Motives on Developers' Action towards Green Redevelopment of Industrial Brownfields
}

\author{
Guangmin Zhang ${ }^{1}$, Yang Zhang ${ }^{2, *}$, Wei Tian ${ }^{1, *} \mathbb{C}$, Huimin $\mathrm{Li}^{1}{ }^{1}$, Ping Guo ${ }^{1} \oplus$ and Fangfang $\mathrm{Ye}^{2}$ \\ 1 School of Civil Engineering, Xi'an University of Architecture and Technology, Xi'an 710055, China; \\ zhanggm@xauat.edu.cn (G.Z.); lihuimin@xauat.edu.cn (H.L.); guoping@xauat.edu.cn (P.G.) \\ 2 School of Management, Xi'an University of Architecture and Technology, Xi'an 710055, China; \\ yff@xauat.edu.cn \\ * Correspondence: zhangyang@xauat.edu.cn (Y.Z.); tianwei@xauat.edu.cn (W.T.); Tel.: +86-1819-240-3900 (Y.Z.); \\ +86-1869-152-6190 (W.T.)
}

check for updates

Citation: Zhang, G.; Zhang, Y.; Tian, W.; Li, H.; Guo, P.; Ye, F. Bridging the Intention-Behavior Gap: Effect of Altruistic Motives on Developers' Action towards Green

Redevelopment of Industrial Brownfields. Sustainability 2021, 13, 977. https://doi.org/10.3390/ su13020977

Received: 17 December 2020

Accepted: 12 January 2021

Published: 19 January 2021

Publisher's Note: MDPI stays neutral with regard to jurisdictional claims in published maps and institutional affiliations.

Copyright: (c) 2021 by the authors. Licensee MDPI, Basel, Switzerland. This article is an open access article distributed under the terms and conditions of the Creative Commons Attribution (CC BY) license (https:// creativecommons.org/licenses/by/ $4.0 /)$.

\begin{abstract}
Green redevelopment (GR) is a promising strategy to deal with industrial brownfields, this sustainable initiation usually fails to be implemented practically in China. Thus, investigating the driving mechanism of developer's GR behavior, as executors of renovation project, is quite essential. The study introduced formative constructs perceived risk (PR) and perceived cost (PC), integrated them with theory of planned behavior (TPB), and extended them by adding two altruistic motives, awareness of responsibility (AR) and awareness of consequence (AC), as moderation variables to explore the bridging role of altruistic motives in GR's intention-behavior gap. Based on 156 developers-oriented field surveys, the study conducted data analysis through partial least square structural equation modeling. It interestingly showed that subjective norm could primarily affect developers' GR behavior, while perceived behavior control is not a significant influencing factor. Meanwhile, adding PR and PC as the additional constructs significantly increased the explanatory power of standard TPB model. Furthermore, the conclusion confirmed altruistic motives AR can distinctly adjust the relationship between GR intention and behavior, whereas AC has no such effect. These findings provide a scientific theoretical basis and a targeted path reference for promoting GR of industrial brownfields.
\end{abstract}

Keywords: industrial brownfields; behavior towards green redevelopment; intention-behavior gap; theory of planned behavior; altruistic motives

\section{Introduction}

Since the reform and opening-up, the scale of industrial land in China has increased from $5104.72 \mathrm{~km}^{2}$ in 2000 to $10,298.65 \mathrm{~km}^{2}$ in 2016 [1,2], and the proportion of urban industrial land in the total urban area is about $20-22 \%$, which is far greater than the $10 \%$ of industrial land across central cities of foreign countries [3]. However, roughly $80 \%$ land of domestic industrial parks is in inefficient use, with $80 \%$ land only generating $20 \%$ tax revenue [4]. The transformations of industrial land have been an inevitable trend of urban renewal and development, which led to enormous tracts of abandoned industrial brownfields in China [5,6]. In addition, adaptive utilization has become a sustainable strategy to tackle problems of industrial brownfields under the impetus of reducing construction investment, intensively saving existing resources and protecting industrial civilization $[7,8]$. However, the research group conducted an in-depth investigation on 148 old industrial redeveloped projects in China's 30 cities during 2015-2018, and found that there are widely many drawbacks in the existed old industrial area recycling projects, such as poor environment, high energy consumption, and lower comfort level. Therefore, the green redevelopment (GR) of industrial brownfields has evolved into a powerful means to save resources, promote sustainable development, and optimize the redevelopment effect [9-12], 
in combination with the environmental background of energy crisis and environmental pollution, and the people's ever-growing needs for a better life under the new era [9].

Green redevelopment of industrial brownfields refers to saving resources by adaptive utilization of industrial buildings, repairing, and protecting the environment to the maximum extent on the premise of meeting the new functional requirements, thus providing people with safe, healthy, and applicable conditions for use, to achieve harmony with society and nature [13]. Real estate developers are the implementers of green redevelopment of industrial brownfields, and their green redevelopment action (GRA) can effectively facilitate the green redevelopment projects development of industrial brownfields and improve the regional environment and redevelopment effect $[14,15]$. Consistent with previous relevant research results [16,17], the study shows that although $70 \%$ of developers have green development intentions, their green initiations instead often fail to be realized in the complex circumstances of project development and construction, thereby leaving the substantive intention-behavior gap. Current studies have shown that altruistic motive is the key factor affecting green behavior [18]. Therefore, establishing GRA conceptual model of industrial brownfields, clarifying the influencing factors and driving mechanism of GRA, and analyzing the bridging role of altruistic motives in green development intention-behavior gap for developers are the key links to promote and optimize the renovation of abandoned industrial areas. Theory of planned behavior (TPB) has been widely recognized in predicting and explaining human behavior, especially in the study of green behavior $[19,20]$. From the above conditions, this paper applies the extended $\mathrm{TPB}$ as the theoretical basis, adopts partial least square structural equation modeling, and carries out the investigation and interview towards developers from 156 old industrial building redevelopment projects in 16 cities throughout China as the data source to verify the explanation of GRA conceptual model of industrial brownfields, so as to provide a scientific theoretical basis for guiding and developing green redevelopment projects of industrial brownfields.

\section{Literature Review and Hypotheses}

\subsection{Reviews on the Theory of Planned Behavior}

Theory of Planned Behavior (TPB), proposed by Ajzen in 1985, is an extension of Theory of Reasoned Action, and is mainly applied to explain and predict human behaviors. According to the TPB theory, behavior is directly influenced by behavioral intention, while behavioral intention (BI) is mainly affected by attitude (AT), subjective norm (SN), and perceived behavioral control (PBC). Many scholars have verified the applicability of TPB in green behavior, namely all behaviors and actions that can lessen environmental pollution and maintain sustainable development of the environment. For example, Lao Kefu (2013) studied the mechanism of the external factors influence on consumers' green consumption behaviors based on TPB model, and validated the significant influences of AT, SN, and PBC on green behavior [19]; on the basis of TPB model, Shwu-Ing Wu (2014) added the influencing factors of perceived benefit, perceived risk, moral obligation, control intensity and control belief, and discussed the effect of green intention on consumption behavior with AT, SN, and PBC as intermediate variables [21]; Han (2015) integrated TPB model and value-belief-norm model, and verified the abilities of $\mathrm{AT}, \mathrm{SN}$, and $\mathrm{PBC}$ to predict the environmentally friendly behaviors of travelers in green accommodation [18]; and Shijing Yang (2019) analyzed the green purchasing problems of developers with TPB model, and proved that $\mathrm{AT}, \mathrm{SN}$, and $\mathrm{PBC}$ exerted great effects on the green purchasing behavior of developers [15].

In summary, based on previous studies, this paper takes the following hypotheses:

Hypotheses 1 (H1): AT has a positive driving effect on developer's GR intention.

Hypotheses 2 (H2): SN has a positive driving effect on developer's GR intention.

Hypotheses 3 (H3): PBC has a positive driving effect on developer's GR intention. 
Hypotheses 4 (H4): GR intention has a positive driving effect on developer's GRA.

\subsection{Perceived Risk}

Perceived risk (PR) shows individuals' subjective beliefs about the possible negative consequences of their decisions [22]. Compared with general projects, the risk of green buildings has been widely discussed and confirmed by scholars and practitioners at home and abroad [23,24]. For example, Yu-Shan Chen (2012) pointed out green perceived risk exerts negative effects on green trust and green purchasing intention through analyzing the impact of green perceived value and green perceived risk on green purchasing intention [25]. Upon the basis of TPB-oriented green consumption behavior model, Shwu-Ing, $\mathrm{Wu}$ and C. Jia-Yi (2014) put forward that the perceived risk of green consumption has a significant negative impact on consumers' attitudes and constrains green consumption behaviors [21]. In studying the influence of green consumption perception on the relationship model of green consumption behavior, Shwu-Ing Wu (2015) divided the perceived risk into four dimensions, including financial risk, social risk, personal risk, and performance risk, and classified research subjects into high green perception group and medium green perception group, and thus concluded that the perceived risk would make a difference to the green behavior intention of the two groups [26]. To summarize, we could make the following assumptions:

Hypotheses 5a (H5a): PR has a negative driving effect on developer's GR attitude.

Hypotheses 5b (H5b): PR has a negative driving effect on the developer's GR intention.

Hypotheses 5c (H5c): PR positively influences GR intention through AT.

\subsection{Perceived Cost}

Cost is an important factor that affects the investment decision of developers. V.A. Zeithaml (1988) proposed that the perceived cost (PC) is the sum of the costs and benefits paid to obtain and use certain service or products [27]. For this study, perceived cost is the sum of time, money, and energy that developers have to invest to consider the whole life cycle of the green redevelopment project of the industrial brownfields. Reed P (1999) conducted three experiments to examine the impact of perceived cost on investment activities and proved that PC could bring about changes to investment judgment [28]. Pearce et al. (2008) believed that the improvement of PC would make developers negative about green building development, and at the same time restrict their development intentions [16]. Li, Jian Xin (2013), when understanding and predicting consumers' environmental resistance behavior from the aspect of green consumption, held that consumers' PC exerts significant negative impacts on their resistance behavior intention [29]. In terms of green buildings development, many studies have generally believed the incremental costs generated by green buildings are one of the core obstacles to the promotion of green buildings [16,30]. As a result, the study formulates some hypotheses as follows:

Hypotheses 6a (H6a): PC has a negative driving effect on the developer's GR intention.

Hypotheses 6b (H6b): PC has a negative driving effect on developer's attitude towards GR.

Hypotheses 6c (H6c): PC positively influences GR intention through AT.

\subsection{Altruistic Motives}

Altruistic Motives is an individual's motivation to help others on the premise of willingness without return [31]. Since TPB is a rational choice model, the design of questionnaire items mainly focuses on self-interest rather than the influence of developer's social attributes on their behaviors, such as the role of altruistic motives in shaping their behaviors [32]. For the analysis about influencing factors of intention-behavior gap, the paper thus introduces the altruistic motive to explore whether it can give rise to the intention- 
behavior gap. To do so, two constitutive aspects containing ascription of responsibility (AR) and awareness of equality (AC) are selected correspondingly. According to the norm activation model, the activation of expected personal norm for individuals to achieve specific behaviors in particular situations depends on AR and AC [33,34]. Specifically, $A R$ refers to individual responsibilities for adverse consequences, while AC refers to the individual consciousness of causing negative consequences to others or other things without implementing specific acts [33]. Wang Y.M (2020) indicated that the green degree of product, utility and social welfare involved in the green supply chain were all affected by altruistic motives, and these motives instead produced a positive effect on the overall utility of the green supply chain [34]. In addition, AR and AC have already been applied with TPB to explain and predict environmentally friendly behaviors $[35,36]$ and the studies show that sustainable behaviors are subject to the influences of AR and AC. Intuitively, the higher the AC or AR, the greater probability of implementing from intention to behavior.

To study whether altruistic factors might influence developers who support GR to transform such green initiations into reality, and verify the key factors in bridging GR intention-behavior gap, the following hypotheses are proposed:

Hypotheses 7 (H7): The relationship between GR intention and GRA is moderated by AC.

Hypotheses 8 (H8): The relationship between GR intention and GRA is moderated by AR.

\subsection{Proposed Model}

For the above analysis, the research uses TPB model as a basis, and introduces external variables (PR and $\mathrm{PC}$ ) and moderation parameters (AR and $\mathrm{AC}$ ) to construct the GRA conceptual model of industrial brownfields, as shown in Figure 1.

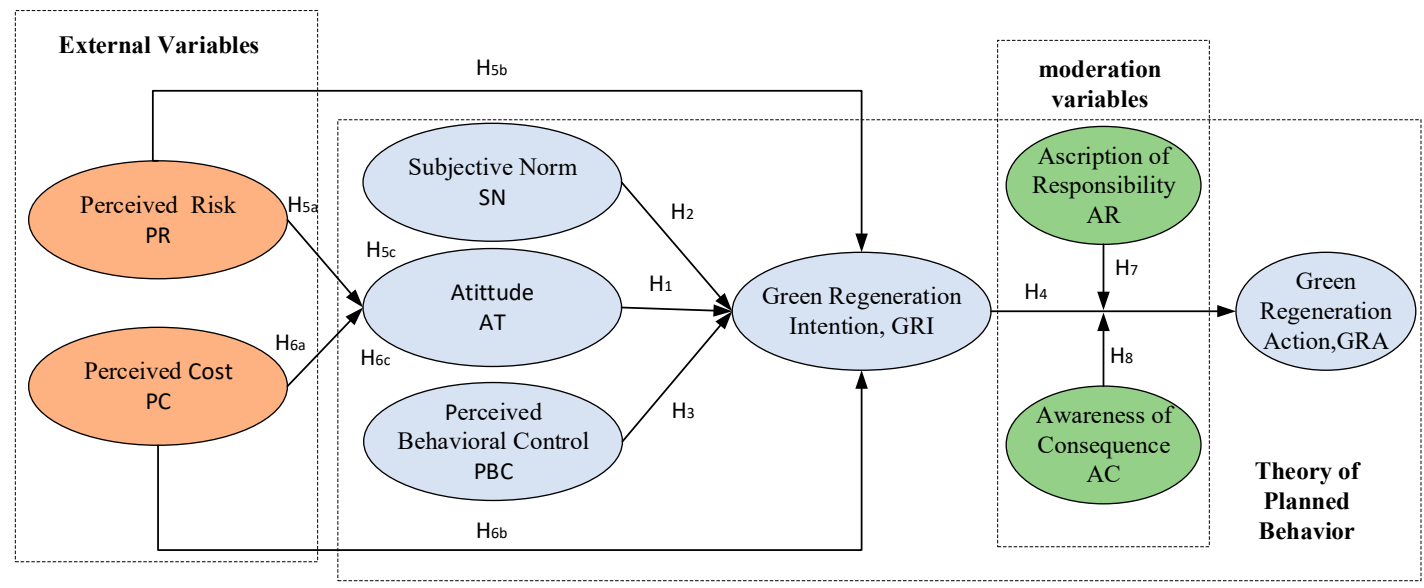

Figure 1. Proposed model.

\section{Research Methodology}

\subsection{Research Framework Overview}

The questionnaire mainly inquired the decision makers' attitudes (AT), subjective norms (SN), perceived behavioral control (PBC), perceived risk (PR), perceived cost (PC), GR intention (GRI), awareness of responsibility (AR), awareness of consequence (AC), and GR action (GRA) towards green redevelopment of industrial brownfields. The research on GRA of industrial brownfields, which is lack of classical questionnaires supports and simply discusses its manifestations rather than the internal causes, cannot deeply search for its driving path. Therefore, the study incorporates the composite model of reflective construct and formal construct, which are indispensable components for research, into the construct setting. Among these two constructs, AT, SN, PBC, GRI, AR, and AC are reflective constructs while PR, PC, and GRA are formative constructs. The items of reflective 
construct were selected with reference to the representative study by Yadav [20] and other scholars, and the titles were appropriately adjusted based on the subjects of the study. Rather, the items of formative construct are primarily derived from the classical literature and engineering practice of scholars such as Li Huimin [37], aiming to further clarify the components of the perceived risk and perceived cost of green redevelopment. The questionnaire adopts the 7 point Likert Scale, where 7 represents the most positive answer and 1 represents the most negative answer. A pretest was conducted on 7 developers of industrial building redevelopment projects in X' $\mathrm{i}^{\prime}$ an and Kunming in October 2016. Difficult and ambiguous items was revised according to the feedback, and a formal investigation questionnaire was formulated. The formal questionnaire questions and reference sources are shown in the Appendix A.

\subsection{Sampling Technique, Procedures, Sample Size, and Composition}

Data was acquired through the questionnaire survey described in Section 3.1. The study conducted a follow-up investigation on the projects under construction to collect data on the actual implementation of the project. Formal research samples were collected from on-site visits of research teams from February 2017 to March 2019. Through on-site visits for 202 developers who have completed or are renovating industrial brownfields in 16 cities (see Figure 2) and a return visit to the actual development results via interview and questionnaires, a total of $156(70 \%)$ valid questionnaires were obtained after deleting the questionnaires of those developers who did not implement the project, not answer questions completely, and did not have the right to make decisions. Besides, the study selected the project attributes and demographic variables, which are commonly used in the research of green redevelopment behavior of industrial brownfields, to carry out statistical analysis on the effective sample structure, as shown in Table 1.

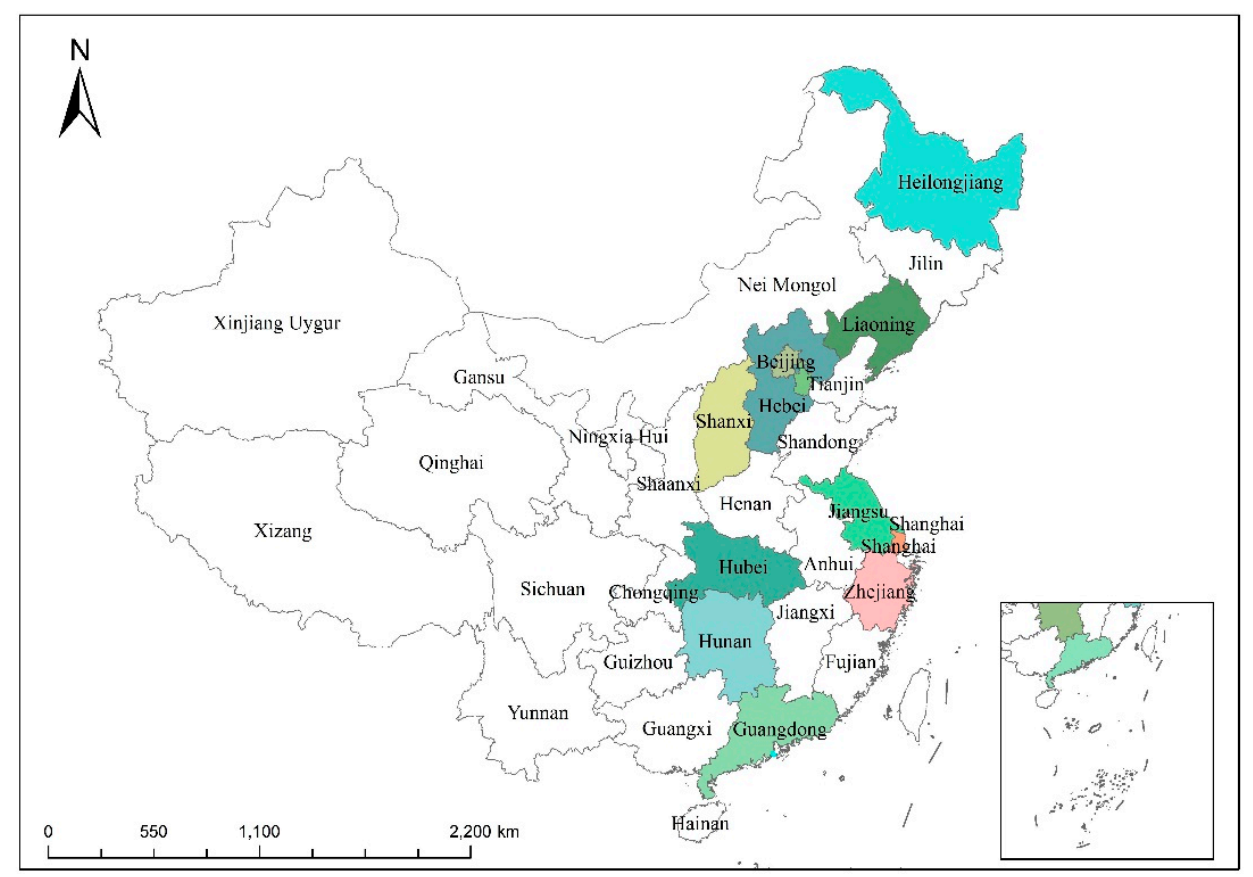

Figure 2. Distribution of data sources. 
Table 1. Demographics of Respondents $(\mathrm{N}=156)$.

\begin{tabular}{|c|c|c|}
\hline Characteristics & $\mathrm{f}^{1}$ & Percent $(\%)^{2}$ \\
\hline \multicolumn{3}{|l|}{ Location } \\
\hline Jing Jin ${ }^{4}$ & 20 & 13 \\
\hline Shanghai & 18 & 12 \\
\hline Guangdong & 40 & 26 \\
\hline Liaoning & 13 & 8 \\
\hline Shanxi & 2 & 1 \\
\hline Heilongjiang & 7 & 4 \\
\hline Zhejiang & 22 & 14 \\
\hline Jiangsu & 14 & 9 \\
\hline Hubei & 10 & 6 \\
\hline Hunan & 10 & 6 \\
\hline \multicolumn{3}{|l|}{ Modes $^{3}$} \\
\hline Creative/Cultural Space & 89 & 57 \\
\hline Office & 25 & 16 \\
\hline Shopping mall & 15 & 10 \\
\hline Housing & 12 & 8 \\
\hline Museum & 7 & 4 \\
\hline Venue Building & 3 & 2 \\
\hline Park & 3 & 2 \\
\hline School & 2 & 1 \\
\hline \multicolumn{3}{|l|}{ Gender } \\
\hline Male & 82 & 53 \\
\hline Female & 74 & 47 \\
\hline \multicolumn{3}{|l|}{ Age } \\
\hline $18-25$ & 3 & 2 \\
\hline $26-30$ & 59 & 38 \\
\hline $31-40$ & 66 & 42 \\
\hline $41-50$ & 24 & 15 \\
\hline $51-60$ & 4 & 3 \\
\hline \multicolumn{3}{|l|}{ Education level } \\
\hline Doctoral & 7 & 4 \\
\hline Post-graduate & 58 & 37 \\
\hline Graduate & 82 & 53 \\
\hline Intermediate & 9 & 6 \\
\hline
\end{tabular}

${ }_{1}^{1} f$ indicates the frequency of the variable response, ${ }^{2} \%$ is the percentage of the variable in total responses, ${ }^{3}$ "Mode" defines the new function of industrial brownfields, "Jing Jin" represents the combined adjacent municipalities of Beijing and Tianjin.

As shown in Figure 2, the data collected in this survey is mainly from the central and western regions of China, which is consistent with the main regional distribution of the recycling projects of industrial brownfields in China. The type of project investigated covers main redevelopment modes of industrial brownfields in China. The proportion of men and women interviewed is roughly equal. Most of the interviewees have a bachelor or master's degree and their ages are relatively under $40(82 \%)$, corresponding with the basic distribution of educational background and age among decision makers of real estate development. To sum up, the samples collected in this study are broadly representative, particularly in terms of demographic variables.

\subsection{Statistical Analysis}

Traditional structural equation modeling (SEM) is not applicable to composite models containing formative variables [17]. Different from SEM, which combines factor analysis and multiple regression analysis, partial least squares-path modeling (PLS-PM) is a kind of iterative algorithm that proposes multivariate statistical analysis based on principal component analysis. After solving the measurement model, PLS-PM could estimate the path coefficients in the structural model, and thus can be considered as an exploratory rather than a confirmatory method [38]. Compared with classical covariance-based SEM (CBSEM), PLS-PM, however, does not seek to reproduce the sample covariance matrix and 
is viewed as a soft modeling method that requires no strong assumptions including distribution, sample size, and measurement scale. According to the research of Henseler et al., PLS-PM requires less sample size than other methods and does not need to meet the requirements of normal distribution. It can also deal with both reflective and formative models simultaneously, and is applicable to theoretical development and prediction. So PLS-PM has been widely used by many scholars in the prediction of behavior $[38,39]$.

As the samples in this study are only from the development decision-makers of the old industrial building recycling project, the sample obtained is small in size $(\mathrm{N}=156)$ and can hardly conform to the normal distribution, but instead it meets the recommended value of PLS-PM to estimate the minimum sample size [38,40]. Meanwhile, the research is built upon TPB model and introduces new latent variables, so it is an exploratory research. The final model designed in this study is a compound model including formative variables, which is the reason why PLS-PM is selected as the data analysis tool for this research. Additionally, Smart-PLS 3.2.8 is one of the methods applied for model analysis. The study chooses appropriate estimation methods with reference to suggestions of Henseler et al. [40] and adopts Path Weighting Scheme as the one to estimate the regression and correlation of the estimated values of latent variables at the same time.

\section{Data Analysis and Results}

\subsection{Outer Model Testing Analysis}

Reliability and validity test. The reliability and validity test methods for reflective variables and formative variables are different from each other. For reflective variables, the measured items are the external manifestations of latent variables, that is, latent variables are causes and items are the corresponding results, and each item should have internal consistency and interchangeability. While for formative variables, the measured items are the internal components of latent variables. In other words, the items are causes and the latent variables therefore are results, there is no internal consistency among the items, and the correlation can be negative [17]. In terms of reflective variables, reliability and validity should be tested at the same time. Composite reliability (CR) and Cronbach's $\alpha$ are used to judge the reliability of each latent variable in the scale. CR and Cronbach's $\alpha$ in this study are both greater than 0.7 (see the sixth and seventh columns of Table 2), which meets the reliability requirements. The convergent validity is tested by fact loading, average variance extracted (AVE) and reliability. According to this research, fact loading items of all reflective variables are greater than 0.6, AVE is greater than 0.6 (see the third and eighth column of Table 2), and CR values are all higher than 0.8 (see the sixth column of Table 2), thus showing better convergence validity. The discriminant validity test is shown in Table 3. Arithmetic square root (in bold) of AVE of each variable is larger than the correlation coefficient of other variables, and thus meets the standard of discriminant validity. With regard to formative variables, their validity should be tested accordingly. In addition to GRA2, the weights of all items are greater than 0.2 and appear significant because $t$-value is greater than 1.96 (see the fourth column of Table 2). Although the weight of GRA2 is less than 0.2 , its factor loading is 0.985 , larger than 0.5 , and can still be retained based on the suggestion of Hair (2014) [41]. However, since the formative variables are essentially negative regression, it is important to check the collinearity contained. The VIF value of each index from this study is less than 5 (see the fifth column of Table 2), and the fact that no collinearity exists meets the standard of validity test [41,42]. Besides, the correlation among all formative variables is less than 0.7 (see Table 3), indicating that this study bears good discriminant validity. 
Table 2. The reliability and validity test for the measurement model.

\begin{tabular}{|c|c|c|c|c|c|c|c|c|}
\hline Items & Mean & $\begin{array}{l}\text { Standard } \\
\text { Deviation }\end{array}$ & $\mathrm{W} / \mathrm{F}$ & $t$-Value & VIF & $\mathrm{CR}^{1}$ & Cronbach's $\alpha$ & $\mathrm{AVE}^{2}$ \\
\hline \multicolumn{9}{|l|}{ Attitude } \\
\hline AT1 & 5.846 & 1.02 & 0.825 & 24.58 & 1.549 & \multirow{3}{*}{0.767} & \multirow{3}{*}{0.866} & \multirow{3}{*}{0.683} \\
\hline AT2 & 5.737 & 0.981 & 0.873 & 38.228 & 1.897 & & & \\
\hline AT3 & 5.923 & 0.836 & 0.779 & 18.216 & 1.501 & & & \\
\hline \multicolumn{9}{|c|}{ Subjective Norm } \\
\hline SN1 & 5.282 & 1.181 & 0.915 & 67.604 & 2.832 & \multirow{3}{*}{0.881} & \multirow{3}{*}{0.927} & \multirow{3}{*}{0.808} \\
\hline SN2 & 5.301 & 1.046 & 0.93 & 85.986 & 3.16 & & & \\
\hline SN3 & 5.206 & 1.039 & 0.85 & 31.275 & 2.039 & & & \\
\hline \multicolumn{9}{|c|}{ Perceived Behavioral Control } \\
\hline $\mathrm{PBC} 1$ & 4.301 & 1.763 & 0.778 & 11.237 & 1.763 & \multirow{4}{*}{0.859} & \multirow{4}{*}{0.903} & \multirow{4}{*}{0.701} \\
\hline PBC2 & 4.679 & 1.446 & 0.882 & 22.852 & 2.37 & & & \\
\hline PBC3 & 4.846 & 1.41 & 0.838 & 16.575 & 2.489 & & & \\
\hline PBC4 & 4.295 & 1.558 & 0.847 & 13.254 & 2.578 & & & \\
\hline \multicolumn{9}{|c|}{ Perceived Risk ${ }^{3}$} \\
\hline PR1 & 2.59 & 1.349 & 0.362 & 2.325 & 1.138 & \multirow{2}{*}{ N.A. } & \multirow{2}{*}{ N.A. } & \multirow{2}{*}{ N.A. } \\
\hline PR2 & 2.788 & 1.276 & 0.814 & 7.987 & 1.138 & & & \\
\hline \multirow{2}{*}{\multicolumn{9}{|c|}{$\begin{array}{l}\text { Perceived } \\
\text { Cost }^{3}\end{array}$}} \\
\hline & & & & & & & & \\
\hline PC1 & 3.859 & 1.734 & 0.623 & 2.322 & 2.707 & \multirow{3}{*}{ N.A. } & \multirow{3}{*}{ N.A. } & \multirow{3}{*}{ N.A. } \\
\hline PC2 & 3.833 & 1.64 & 0.682 & 2.599 & 2.825 & & & \\
\hline PC3 & 4.878 & 1.465 & 0.456 & 1.985 & 1.715 & & & \\
\hline \multicolumn{9}{|c|}{ Green Redevelopment Intention } \\
\hline GRI1 & 5.327 & 1.133 & 0.82 & 24.839 & 2.451 & \multirow{5}{*}{0.886} & \multirow{5}{*}{0.917} & \multirow{5}{*}{0.688} \\
\hline GRI2 & 5.365 & 1.138 & 0.844 & 27.825 & 2.667 & & & \\
\hline GRI3 & 5.282 & 1.224 & 0.833 & 28.978 & 2.305 & & & \\
\hline GRI4 & 5.385 & 1.222 & 0.818 & 27.155 & 2.627 & & & \\
\hline GRI5 & 5.359 & 1.086 & 0.831 & 31.588 & 2.492 & & & \\
\hline \multicolumn{9}{|c|}{ Ascription of Responsibility } \\
\hline AR1 & 2.122 & 1.111 & 0.834 & 2.339 & 2.636 & \multirow{3}{*}{0.865} & & \\
\hline AR2 & 1.929 & 1.11 & 0.732 & 1.911 & 2.775 & & 0.879 & 0.711 \\
\hline AR3 & 2.019 & 1.135 & 0.95 & 2.883 & 1.842 & & & \\
\hline Awareness of Cor & & & & & & & & \\
\hline $\mathrm{AC} 1$ & 5.314 & 1.208 & 0.786 & 2.489 & 1.441 & & & \\
\hline $\mathrm{AC} 2$ & 5.199 & 1.288 & 0.95 & 2.553 & 1.441 & 0.712 & 0.863 & 0.76 \\
\hline Green Redevelopm & & & & & & & & \\
\hline GRA1 & 4.91 & 1.332 & 0.24 & 1.575 & 1.984 & & & \\
\hline GRA2 & 4.468 & 1.521 & 0.816 & 6.484 & 1.984 & N.A. & N.A. & N.A. \\
\hline
\end{tabular}

${ }^{1}$ CR represents composite reliability. ${ }^{2}$ AVE represents average variance extracted. ${ }^{3}$ Perceived Cost, Perceived Risk and Green Redevelopment Action are formative indicators without involving reliability analysis or CR, Cronbach's $\alpha$ and AVE, and are represented as N.A.

\subsection{Inner Model and Hypotheses Testing}

Bootstrapping is the method applied to estimate the significance of each path coefficient. The estimated value, obtained by using repeated sampling data for estimation, is more accurate than the commonly used limit approximate value. Thus, this study employs such a method to test the significant relationship between variables.

Figure 3 shows that AT and SN have a significant positive effect on GRI, PR exerts a significant negative effect on GRI, and positive GRI affects actual behavior in positive ways, which further demonstrates that $\mathrm{H} 1, \mathrm{H} 2$, and $\mathrm{H} 4$ are all supported (AT $\rightarrow$ GRI: $\beta=0.319, \mathrm{~T}$ value $=5.230 ; \mathrm{SN} \rightarrow$ GRI: $\beta=0.377, T$-value $=5.350 ; \mathrm{GRI} \rightarrow \mathrm{GRA}: \beta=0.698, T$-value $=11.790)$. PR casts a significant negative effect on AT and GRI $(P R \rightarrow$ AT: $\beta=-0.323, T$-value $=3.985$; PR $\rightarrow$ GRI: $\beta=-0.192, T$-value $=2.655$ ), and then makes H5a and H55 stand. Consistent 
with the hypothesis, PC causes a significant negative impact on developers' AT and GRI $(\mathrm{PC} \rightarrow \mathrm{AT}: \beta=-0.181, T$-value $=2.138 ; \mathrm{PC} \rightarrow \mathrm{GRI}: \beta=-0.218, T$-value $=3.645)$, which supports the hypothesis of H6a and H6b. In contrast, the statistical results show that PBC has no significant effects on GRI, so H3 is invalid (PBC $\rightarrow$ GRI: $\beta=-0.025, T$-value $=0.411$ ). In the extended model, the R2 of GRI is 0.619 , while the R2 of GRA is 0.469 . Compared with the original TPB (the R2 of GRI is 0.538 , and the R2 of GRA is 0.391 ), it can be reasonably inferred that this model has sufficient and better abilities to predict.

Table 3. Discriminant validity for the measurement model.

\begin{tabular}{ccccccccc}
\hline Construct & AT & SN & PBC & PR $^{\mathbf{1}}$ & PC $^{\mathbf{1}}$ & GRI & AR $^{\text {AC }}$ & GRA $^{\mathbf{1}}$ \\
\hline AT & $\mathbf{0 . 8 2 6}$ & & & & & & \\
SN & 0.482 & $\mathbf{0 . 8 9 9}$ & & & & & \\
PBC & 0.214 & 0.428 & $\mathbf{0 . 8 3 7}$ & & & & \\
PR & -0.360 & -0.289 & -0.217 & N.A. & & & \\
PC & -0.247 & -0.307 & -0.006 & 0.203 & N.A. & & & \\
GRI & 0.618 & 0.642 & 0.247 & -0.455 & -0.451 & $\mathbf{0 . 8 2 9}$ & & \\
AR & -0.164 & -0.093 & 0.030 & 0.077 & 0.055 & -0.246 & $\mathbf{0 . 8 4 3}$ & \\
AC & 0.046 & -0.083 & -0.149 & 0.001 & -0.008 & 0.033 & -0.054 & $\mathbf{0 . 8 7 2}$ \\
GRA $^{1}$ & 0.369 & 0.474 & 0.338 & -0.456 & -0.320 & 0.624 & -0.071 & -0.116 \\
\hline
\end{tabular}

${ }^{1}$ PC, PR and GRA are formative indicators without average variance extracted (AVE), and are represented as N.A. Diagonal bold types are the square root of AVE of corresponding latent variables.

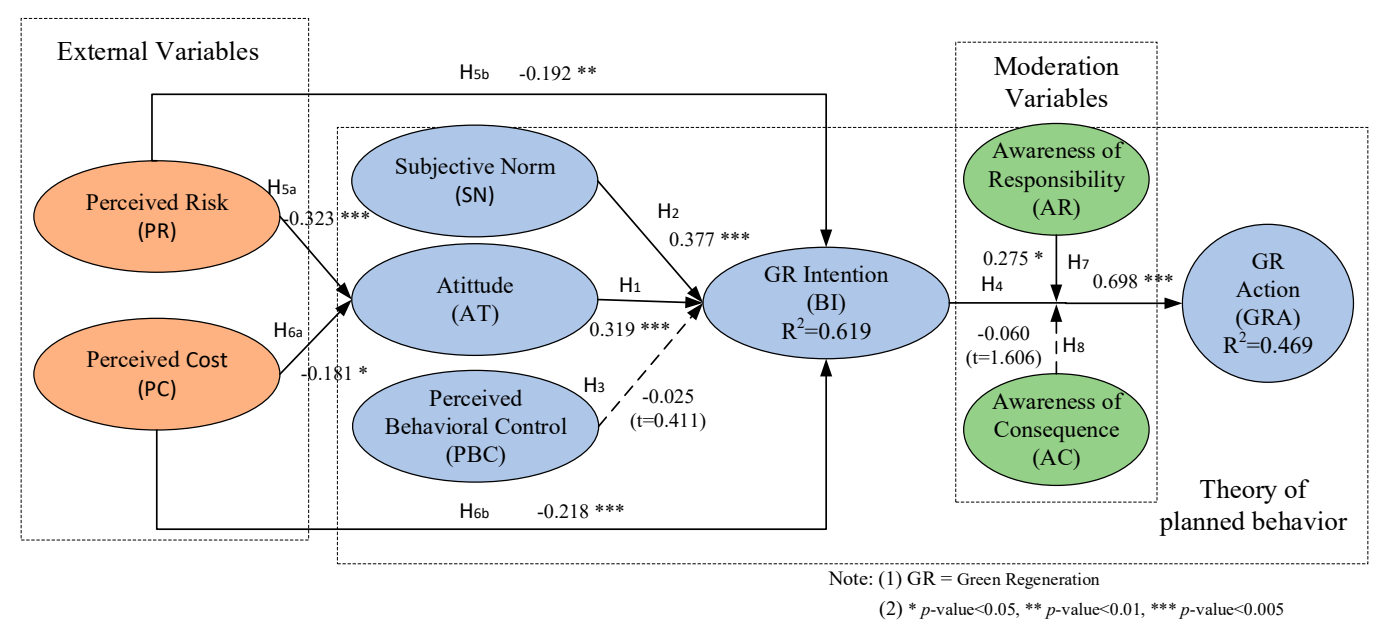

Figure 3. Path coefficient and significance of structural model (bootstrapping $=5000$ ).

\subsection{Mediation Effect Testing}

This study adopts bootstrapping to conduct path analysis so as to test whether the mediation model proposed in this study is statistically significant. When the $T$ value of the mediation path is greater than 1.96, the mediation effect is significant (the results of the mediation test are shown in Table 4).

Table 4. Mediation effect testing (number of bootstrap samples $=5000$ ).

\begin{tabular}{cccc}
\hline Relationship & Original Sample & $\boldsymbol{t}$-Value & Significant \\
\hline H5C: PR -> AT -> GRI & -0.103 & $3.058^{* * *}$ & YES \\
H6C: PC -> AT -> GRI & -0.058 & $2.065^{*}$ & YES \\
\hline Note: ${ }^{*} p$-value $<0.05,^{* * *} p$-value $<0.005$. & &
\end{tabular}

\subsection{Moderation Effect Testing of Altruistic Motives}

A moderator specified the condition under which the strength of an effect varies [43]. According to the method proposed by Chin (2003) [44], the moderation effect testing of this 
study was conducted using $\mathrm{AB}$ as a dependent variable, while $\mathrm{AR}$ and $\mathrm{AC}$ as the moderator variables, while selecting GRI as the independent variable respectively for interaction. After mean centered of $A R, A C$, and GRI, the variables $A R \times G R I$ and $A R \times G R I$ were generated for evaluate, the variables $A C \times G R I$ and $A R \times G R I$ are generated for evaluation. The results of the moderation effect tests are shown in Table 5.

Table 5. Moderator effects testing (number of bootstrap samples = 5000).

\begin{tabular}{cccccc}
\hline $\begin{array}{c}\text { Dependent } \\
\text { Variable }\end{array}$ & $\begin{array}{c}\text { Moderator } \\
\text { Variable }\end{array}$ & $\begin{array}{c}\text { Independent } \\
\text { Variable }\end{array}$ & $\begin{array}{c}\text { Original } \\
\text { Sample }\end{array}$ & $\boldsymbol{t}$-Value & Result \\
\hline AB & GRI & AR & 0.274 & $2.164 *$ & $\begin{array}{c}\text { H7: } \\
\text { Supported } \\
\text { H8: Not } \\
\text { Supported }\end{array}$ \\
\hline Note* ${ }^{*} p$-value $<0.05$ & AC & 0.060 & 1.05 &
\end{tabular}

Note: ${ }^{*} p$-value $<0.05$

\section{Discussion and Conclusions}

\subsection{Discussion}

According to the study, the extended TPB composite model including expansion variables such as PR and PC is applied to the analysis of influencing factors of GRA in industrial brownfields, and the applicability of the extended model to this study is verified by quantitative analysis of 156 questionnaires for developers. Generally, it was found from the empirical testing that extended TPB model is strongly supported by questionnaire responses and most paths are significant in the assumed direction. Therefore, the extended TPB model is conductive to explaining the green redevelopment actions of developers on industrial brownfields more comprehensively. In addition, this study reveals the intentionbehavior gap on green redevelopment action, and discovers that awareness of responsibility can promote the transformation from intention to behavior. Other findings of the study are as follows:

1. Consistent with previous studies [45,46], AT and SN do generate certain influences on developers' green redevelopment intention based on the original TPB model. Subjective norms exert the greatest effects on the behavior intention of green redevelopment of industrial brownfields $(\beta=0.377)$, which shows that personal values are easily vulnerable to policies and social mainstream values. That attitude could also have a positive driving effect on behavior intention indicates that developers' likes and dislikes or subjective preferences of green redevelopment will directly affect their intentions to develop such projects. The intention of green redevelopment behavior directly stimulates green behavior $(\beta=0.698)$. However, perceptual behavior control has no statistical significance on developers' green redevelopment behavior intention. As for its cause, due to many subjects, high cost, complicated construction procedure, and long construction period involved, developers often act as certain roles of project sponsors, fund raisers, and decision makers during the development process of construction projects. Their current knowledge, technology, and funds have no significant driving effects on the development intention of green recycling projects. Considering the influence of subjective norms on the intention of green redevelopment, from the perspective of the state and local governments, guiding incentive policies should be formulated to encourage the transformation of industrial brownfields through green redevelopment. Meanwhile, local governments have to put priorities on supporting and encouraging developers with industry influence to carry out green recycling practice, establish green recycling demonstration projects for industrial brownfields, and take advantage of their appeal to develop green recycling industry trends. Additionally, in combination with the influence of attitude, it is necessary for the government, when promoting green redevelopment, to create an atmosphere of "green development" through multiple channels, publicize the positive effects of green redevelopment on the site environment and using experience in a 
sustained and diverse way, and emphasize its outstanding value for sustainable development and building a conservation-oriented society on the basis of disclosure of information about shortage of land resources $[47,48]$. Only by doing so can the green redevelopment develop as a transformation mode widely recognized and respected across society.

2. Among the newly introduced variables, both perceived risk and perceived cost have a significant negative impact on the attitude and behavior intention of green redevelopment, and take attitude as the intermediary to affect the intention of green development and facilitate the green redevelopment behavior. Perceived risk specifically is responsible for its significant negative impacts on the attitude and behavior intention of green redevelopment of industrial brownfields. The practice of green recycling of industrial brownfields in China remains under the exploratory stage. At the policy level, the policy orientation and operation process of recycling industrial brownfields in some provinces and cities are vague or unclear, which virtually increases the policy risks of green recycling of industrial brownfields. While at the implementation level, there is also a lack of applicable authoritative standards to guide the specific work. The existed green building evaluation criteria mainly focus on newly-built projects, and puts great emphasis on building structure design and green technology application, but seems unable to solve the targeted problems of recycling of industrial brownfields and reflect the inherent advantages of recycling in "green development", thus making it more difficult to apply for green building identification for such projects. Having stated the above, apart from the efforts of developers, government departments should also provide clearer, simpler, and more open policies for the recycling and development of industrial brownfields, and formulate a complete and transparent regulatory system for the recycling and utilization of industrial brownfields in the effort to reduce perceived risks. The development of green redevelopment project of old industrial building can be guided and encouraged by establishing a more suitable evaluation criterion. Based on the direct influence of perceived cost on the attitude and intention of green redevelopment of industrial brownfields, it can be inferred that: (1) during the process of promoting green redevelopment of industrial brownfields, it is necessary to focus on reducing the incremental costs caused by materials, equipment and technical services related to green redevelopment; (2) when in the assessment of green buildings, the old industrial building renovation project, as a way to utilize existing resources sustainably, should be laid great stress on the detection, verification and recycling of resources, the adaptive renovation of spatial pattern and thermal insulation performance, and the repair and improvement of the overall environmental styles or features, rather than the superposition of new green technologies that would affect the original structure. Through the formulation and promulgation of more applicable evaluation criteria for green redevelopment of industrial brownfields, redevelopment projects no longer need to lean on high-cost technology to ensure certain scores, but instead can achieve the reasonable reduction of the cost of green redevelopment project of industrial brownfields as well; and (3) efforts can also be made to constantly boost and implement the financial subsidy policy for green buildings, and rationally spilt the incremental cost of green redevelopment of industrial brownfields in the way of implementing incentive policies such as incentive floor area ratio, reduction, or return of urban building supporting fees.

3. Although most real estate developers undoubtedly show a high willingness to green redevelopment of industrial brownfield, a large number of developers still fail to perform it in reality. This has inspired the study to investigate the reasons for the intention-behavior gap by introducing awareness of responsibility and awareness of consequence in explorative ways, to test whether altruistic motives can promote the transformation of developers' green development intentions to development behavior. 
In bridging the effect of altruistic motives on intention-behavior, responsibility consciousness moderates the effects of developers' green redevelopment intentions on green redevelopment behavior, indicating that when developers are conscious that they shoulder joint responsibilities for green redevelopment, their willingness to transform green redevelopment intention into green redevelopment behavior will be stronger. However, the awareness of consequence would not interfere with the relationship between green redevelopment intention and redevelopment behavior. In other words, the transition from "want to do" to "really do" will not be changed by the AC from subjects. The underlying reason is that real estate developers in essence are still the groups to seek profit [49]. Alternatively, the fact that green redevelopment could have positive influences on others makes no difference to the green generation practices of developers. Only when their responsibilities are internalized can developers effectively put green development into practice. In a way to increase the implementation probability of developers, the government should underscore the intensity and determination of national environmental protection, strengthen the management of real estate businesses, and make them clear about the new situation of environmental rule of law and the legal responsibility for ecological environmental protection. Furthermore, the government should actively disclose the environmental problems caused by inefficient development of industrial land, with special emphasis on the responsibility of developers and the consequences they have to pay in the process, as part of efforts to further internalize green redevelopment into the environmental responsibility of developers.

The research model contributes to understand the driving factors of green redevelopment of industrial brownfields, and explores the influence mechanism of each factor on green redevelopment behavior. It proves that altruistic motives can bring out changes in bridging the intention-behavior of developers in green development. Meanwhile, this study establishes a theoretical basis for the formulation of relevant policies. For the government, robust and instructive policies and operational norms towards brownfield redevelopment should be formulated, green evaluation standards with corresponding reward and punishment measures of brownfield redevelopment should be enacted. In the government's management of developers, green redevelopment can be incorporated into the performance system of brownfield governance, which can be used as an important index to evaluate brownfield developers. Additionally, this empirical test also verifies the feasibility of TPB model in studying the specific development behavior of developers. By setting expansion variables and moderation variables, the research can analyze the mechanism of each factor comprehensively and effectively. The application of extended TPB to investigate stakeholders' preferences for urban reconstruction design and implementation is a new field with great potential in future research.

\subsection{Research Limitations and Future Work}

There still exist some limitations in this study that need to be solved in future studies. To begin with, the hypothesis model of this study is to analyze the influencing factors of green redevelopment behavior of industrial brownfields from the perspective of developers. The applicability of this extended TPB model thus can be further tested from the point of other stakeholders in future. Furthermore, there are different functions derived from industrial brownfields, covering creative or cultural space, shopping mall and museums, and these different building functions will inevitably bear certain differences in the driving factors for developers' green redevelopment behavior. It is thus necessary to consider different functions for investigation and evaluation, and find out the differences of driving factors for green redevelopment behavior. Last but not least, the data involved is all collected from China. Due to the differences in environment and policies within different countries, it has not been confirmed whether the conclusions of this study are applicable to other countries. Therefore, the green redevelopment cases in other countries and regions should be comprehensively taken into consideration in future research. 
Author Contributions: Conceptualization, H.L.; formal analysis, G.Z., Y.Z., W.T.; writing-original draft, G.Z., Y.Z.; writing—review and editing, Y.Z., W.T., P.G., F.Y.; funding acquisition, W.T., H.L. All authors have read and agreed to the published version of the manuscript.

Funding: This research was funded by the National Natural Science Foundation of China, grant numbers 51808424, 51677879; the Shaanxi Provincial Basic Research Program of Natural Science, grant number 2020JQ-690.

Institutional Review Board Statement: Not applicable.

Informed Consent Statement: Informed consent was obtained from all subjects involved in the study.

Data Availability Statement: The data presented in this study are available on request from the corresponding author. The data are not publicly available due to privacy or ethical restrictions.

Acknowledgments: We would like to thank Fang Qiao for English language editing support.

Conflicts of Interest: The authors declare no conflict of interest.

\section{Appendix A}

Table A1. Questionnaire on Action Toward Green Redevelopment of Industrial Brownfields.

\begin{tabular}{lll}
\hline Constructs & \multicolumn{1}{c}{ Items } \\
\hline \multirow{3}{*}{ Attitude } & AT1 I think GR is beneficial. \\
& AT2 I think GR is good. \\
& AT3 I think GR of industrial buildings is wise. \\
& SN1 The national policy supports the use of GR to deal with \\
& industrial brownfields. \\
& SN2 People in the line of business tend to use GR to deal \\
Subjective Norm & with industrial brownfields. \\
& SN3 The public prefers to deal with industrial brownfields \\
& through GR. \\
\hline & PBC1 I can make GR decisions independently. \\
& PBC2 I have enough knowledge and information to carry \\
Perceived Behavioral Control & out GR decision-making and management. \\
& PBC3 I have enough money to deal with the difficulties \\
& occurred in GR process. \\
& PBC4 I have enough time to deal with the difficulties \\
& occurred in GR process. \\
\hline
\end{tabular}
occurred in GR process.

Perceived Risk

PR1 Due to the lack of applicable standards and technologies, the later certification results cannot be guaranteed.

PR2 The unclear old industrial building recycling policy will incur greater risks to GR incremental investment.

PC1 Design cost: the design cost of GR project is higher than

Perceived Cost that of general project.

PC2 Construction cost: GR could generate greater investment in the construction process.

PC3 Operation cost: the operation and maintenance cost of GR project is relatively higher. 
Table A1. Cont.

\begin{tabular}{|c|c|c|}
\hline Constructs & Items & Source \\
\hline Green Redevelopment Intention & $\begin{array}{l}\text { GRI1 I will adopt GR strategy if I want to renovate old } \\
\text { industrial buildings. } \\
\text { GRI2 I would recommend GR strategy if others carry out } \\
\text { renovation of industrial brownfields } \\
\text { GRI3 I will tell others the advantages of GR. } \\
\text { GRI4 I hope GR strategy can be adopted to deal with } \\
\text { industrial brownfields in the future. } \\
\text { GRI5 If I have carried out the GR of the old industrial } \\
\text { building and I would renovate another old industrial } \\
\text { building again, I will still adopt GR strategy. }\end{array}$ & [18] \\
\hline Ascription of Responsibility & $\begin{array}{l}\text { AR1 As a developer, I should be responsible for the } \\
\text { environmental problems caused by not adopting GR. } \\
\text { AR2 As a developer, I should be responsible for the waste of } \\
\text { resources caused by not adopting GR. } \\
\text { AR3 As a developer, I should be responsible for the poor } \\
\text { use effect caused by not adopting GR. }\end{array}$ & [37] \\
\hline Awareness of Consequence & $\begin{array}{l}\text { AC1 Without GR, the environment would suffer great } \\
\text { damage. } \\
\text { AC2 Without GR, the health and convenience of users will } \\
\text { be adversely affected. }\end{array}$ & {$[37,53]$} \\
\hline Green Redevelopment Action & $\begin{array}{l}\text { GRA1 The project has been evaluated as } \\
\text { green/energy-saving building/energy-saving } \\
\text { demonstration park. } \\
\text { GRA2 I have made full use of green technology measures in } \\
\text { the renovation project. }\end{array}$ & [37] \\
\hline
\end{tabular}

\section{References}

1. NBSP. China Urban Construction Statistics Yearbook Official, 1st ed.; Architecture \& Building Press: Beijing, China, 2000.

2. MOHURD. China Urban Construction Statistics Yearbook Official, 1st ed.; Official of China Statistics Publishing House: Beijing, China, 2016.

3. Jia, H.J.; Huang, X.J.; Yu, S.T.; Wang, G.H.; Zheng, Z.Q. Status of Intensive Use of Industrial Land in China and the Countermeasures for Improving It. China Land Sci. 2010, 24, 52-56. [CrossRef]

4. Shi, J.G.; Xu, T.H. Efficiency evaluation of industrial parks land in Yangtze River Urban Agglomerations based on VRS-DEA Model and Malmquist Productivity Index. Res. Sci. 2017, 39, 1026-1036.

5. Wu, Q.; Zhang, X.; Liu, C.; Chen, Z. The de-industrialization, re-suburbanization and health risks of brownfield land reuse: Case study of a toxic soil event in Changzhou, China. Land Use Policy 2018, 74, 187-194. [CrossRef]

6. Zhang, Y.; Wang, C.; Tian, W.; Zhang, G. Determinants of purchase intention for real estate developed on industrial brownfields: Evidence from China. Neth. J. Hous. Environ. Res. 2020, 35, 1261-1282. [CrossRef]

7. Pittau, F.; Bande, L.; Beacco, D.; Passera, A.; Angelis, E.D.; Fumagalli, C. Brownfields regeneration as a smart growth option and building technologies: The case study of "La Goccia Di Bovisa" in Milano. In Proceedings of the International Conference on Engineering \& Technology, Bandar Seri Begawan, Burnei, 1-3 November 2014. [CrossRef]

8. Glumac, B.; Han, Q.; Schaefer, W.; Van Der Krabben, E. Negotiation issues in forming public-private partnerships for brownfield redevelopment: Applying a game theoretical experiment. Land Use Policy 2015, 47, 66-77. [CrossRef]

9. He, Q.; Zhao, H.; Shen, L.; Dong, L.; Cheng, Y.; Xu, K. Factors Influencing Residents' Intention toward Green Retrofitting of Existing Residential Buildings. Sustainability 2019, 11, 4246. [CrossRef]

10. Cascone, S.; Catania, F.; Gagliano, A.; Sciuto, G. A comprehensive study on green roof performance for retrofitting existing buildings. Build. Environ. 2018, 136, 227-239. [CrossRef]

11. Gou, Z. Green building for office interiors: Challenges and opportunities. Facilities 2016, 34, 614-629. [CrossRef]

12. Langston, C.G. Adaptive Reuse: Issues and Strategies for the Built Environment. In Modeling Risk Management in Sustainable Construction. Computational Risk Management; Wu, D., Ed.; Springer: Berlin/Heidelberg, Germany, 2011. [CrossRef]

13. Li, H.M.; Chen, X.; Meng, H.; Zhang, J.; Tian, W.; Zhang, Y.; Jia, L.X.; Li, Q.; Gao, M.Z.; Pei, X.W.; et al. Technical Standard for the Regeneration of Old Industrial Building, 1st ed.; Metallurgical Industry Press: Beijing, China, 2016.

14. Fadeyi Moshood, O.; Jallow Abdou, K.; Anumba, C.; Dulaimi, M. Process Management Approach for Achieving Total Building Performance: Essential Requirements for Sustainable Construction. In Proceedings of the Architectural Engineering Conference, State College, PA, USA, 3-5 April 2013. 
15. Yang, S.; Su, Y.; Wang, W.; Hua, K. Research on Developers' Green Procurement Behavior Based on the Theory of Planned Behavior. Sustainability 2019, 11, 2949. [CrossRef]

16. Pearce, A.R. Sustainable capital projects: Leapfrogging the first cost barrier. Civ. Eng. Environ. Syst. 2008, 25, 291-300. [CrossRef]

17. Fornell, C.; Bookstein, F.L. Two structural equation models: LISREL and PLS applied to consumer exit-voice theory. J. Mark. Res. 1982, 19, 440. [CrossRef]

18. Han, H. Travelers' pro-environmental behavior in a green lodging context: Converging value-belief-norm theory and the theory of planned behavior. Tour. Manag. 2015, 47, 164-177. [CrossRef]

19. Lao, K.F.; Wu, J. Research on Influencing Mechanism of Consumer Green Consumption Behavior Referring to TPB. Financ. Econ. 2013, 2, 91-100. [CrossRef]

20. Yadav, R.; Pathak, G.S. Determinants of Consumers' Green Purchase Behavior in a Developing Nation: Applying and Extending the Theory of Planned Behavior. Ecol. Econ. 2017, 134, 114-122. [CrossRef]

21. Wu, S.-I.; Chen, J.-Y. A model of green consumption behavior constructed by the theory of planned behavior. Int. J. Mark. Stud. 2014, 6, 119. [CrossRef]

22. Dowling, G.R.; Staelin, R. A Model of Perceived Risk and Intended Risk-Handling Activity. J. Consum. Res. 1994, 21, 119-134. [CrossRef]

23. Chan, L.Y.; Wang, E.M. Study on Decision Risk of Green Building. J. Eng. Manag. 2016, 30, 86-90. [CrossRef]

24. Tulacz, G. Insurers worry about green-building risks. ENR Eng. News Rec. 2008, 261, 10-11.

25. Chen, Y.; Chang, C. Enhance green purchase intentions: The roles of green perceived value, green perceived risk, and green trust. Manag. Decis. 2012, 50, 502-520. [CrossRef]

26. Wu, S.I. Effect of Green Consumption Perception Degree on Relationship Model of Green Consumption Behavior. J. Manag. Strat. 2015, 6, p109. [CrossRef]

27. Zeithaml, V.A. Consumer perceptions of price, quality, and value: A means-end model and synthesis of evidence. J. Mark. 1988, 52, 2-22. [CrossRef]

28. Reed, P. Effect of perceived cost on judgments regarding the efficacy of investment. J. Econ. Psychol. 1999, 20, 657-676. [CrossRef]

29. Li, J.X.; Gong, X. Determinants of Consumer Environment Boycott Behavior: Based on the Theory of Planned Behavior. Adv. Mat. Res. 2013, 808, 923-926. [CrossRef]

30. Dwaikat, L.N.; Ali, K.N. Green buildings cost premium: A review of empirical evidence. Energy Build. 2016, 110, 396-403. [CrossRef]

31. Batson, C.D.; Shaw, L.L. Evidence for Altruism: Toward A Pluralism of Prosocial Motives. Psychol. Inq. 1991, 2, 107-122. [CrossRef]

32. Kaiser, F.G.; Ranney, M.; Hartig, T.; Bowler, P.A. Ecological Behavior, Environmental Attitude, and Feelings of Responsibility for the Environment. Eur. Psychol. 1999, 4, 59-74. [CrossRef]

33. Schwartzs, H. Normative influences on altruism. Adv. Exp. Soc. Psychol. 1977, 10, 221-279.

34. Yongming, W.; Wenjuan, J.; Hongli, Y. Research on Coordination of Manufacturers' Altruistic Green Supply Chain Contract Based on Gvernment Subsidy. Sci. Technol. Econ. 2020, 22, 6-10.

35. De Groot, J.I.; Steg, L. Morality and prosocial behavior: The role of awareness, responsibility, and norms in the norm activation model. J. Soc. Psychol. 2009, 149, 425-449. [CrossRef]

36. Zhang, L.; Hu, Q.; Zhang, S.; Zhang, W. Understanding chinese residents' waste classification from a perspective of intentionbehavior gap. Sustainability 2020, 12, 4135. [CrossRef]

37. Li, H. The Generality of the Green Regeneration of Old Industrial Buildings, 1st ed.; Architecture \& Building Press: Beijing, China, 2017.

38. Vinzi, V.E.; Trinchera, L.; Amato, S. PLS path modeling: From foundations to recent developments and open issues for model assessment and improvement. In Handbook of Partial Least Squares; Springer: Berlin/Heidelberg, Germany, $2010 ;$ pp. 47-82.

39. Hair, J.; Sarstedt, M.; Ringle, C.M.; Mena, J.A. An assessment of the use of partial least squares structural equation modeling in marketing research. J. Acad. Mark. Sci. 2012, 40, 414-433. [CrossRef]

40. Henseler, J.; Chin, W.W. A comparison of approaches for the analysis of interaction effects between latent variables using partial least squares path modeling. Struct. Equ. Model. A Multidiscip. J. 2010, 17, 82-109. [CrossRef]

41. Hair, J.F., Jr.; Sarstedt, M.; Hopkins, L.; Kuppelwieser, V.G. Partial least squares structural equation modeling (PLS-SEM). Eur. Bus. Rev. 2014, 26, 106-121. [CrossRef]

42. Chin, W.W. The partial least squares approach to structural equation modeling. Mod. Methods Bus. Res. 1998, 295, 295-336.

43. Baron, R.M.; Kenny, D.A. The moderator-mediator variable distinction in social psychological research: Conceptual, strategic, and statistical considerations. J. Pers. Soc. Psychol. 1986, 51, 1173-1182. [CrossRef] [PubMed]

44. Chin, W.W.; Marcolin, B.L.; Newsted, P.R. A partial least squares latent variable modeling approach for measuring interaction effects: Results from a Monte Carlo simulation study and an electronic-mail emotion/adoption study. Inf. Syst. Res. 2003, 14, 189-217. [CrossRef]

45. Mahmud, S.N.D.; Osman, K. The determinants of recycling intention behavior among the Malaysian school students: An application of theory of planned behaviour. Procedia Soc. Behav. Sci. 2010, 9, 119-124. [CrossRef]

46. Han, H.S.; Sungil, L.; Choongki, L. Extending the theory of planned behavior: Visa exemptions and the traveler decision-making process. Tour. Geogr. 2011, 13, 45-74. [CrossRef] 
47. Hou, C.X.; Wen, Y.; Liu, X.J.; Dong, M. Impacts of Regional Water Shortage Information Disclosure on Public Acceptance of Recycled Water-Evidences from China's Urban Residents. J. Clean. Prod. 2020, 278, 123965. [CrossRef]

48. Hou, C.; Fu, H.; Liu, X.; Wen, Y. The Effect of Recycled Water Information Disclosure on Public Acceptance of Recycled Water-Evidence from residents of Xi'an, China. Sustain. Cities Soc. 2020, 61, 102351. [CrossRef]

49. Zachary, H. Giving back to get ahead: Altruism as a developer strategy of accumulation through affordable housing policy in Toronto and Vancouver. Geoforum 2018. [CrossRef]

50. Yadav, R.; Pathak, G.S. Young consumers' intention towards buying green products in a developing nation: Extending the theory of planned behavior. J. Clean. Prod. 2016, 135, 732-739. [CrossRef]

51. Tiraieyari, N.; Krauss, S.E. Predicting youth participation in urban agriculture in Malaysia: Insights from the theory of planned behavior and the functional approach to volunteer motivation. Agric. Hum. Values 2018, 35, 637-650. [CrossRef]

52. Jang, S.Y.; Chung, J.Y.; Kim, Y.G. Effects of Environmentally Friendly Perceptions on Customers' Intentions to Visit Environmentally Friendly Restaurants: An Extended Theory of Planned Behavior. Asia Pac. J. Tour. Res. 2015, 20, 599-618. [CrossRef]

53. Li, L.; Ming, H.; Yang, R.; Luo, X. The impact of policy factors and users' awareness on electricity-saving behaviors: From the perspective of habits and investment. Sustainability 2020, 12, 4815. [CrossRef] 